\title{
JÜRGEN HABERMAS: O PROBLEMA DO NATURALISMO FRACO E A NOVA PERSPECTIVA SOBRE VERDADE E JUSTIFICAÇÃO
}

\author{
Jürgen Habermas: the problem of weak naturalism and the new perspective on Truth and \\ Justification \\ Juliano Cordeiro da Costa Oliveira*
}

Resumo: O artigo debate como Habermas, em Verdade e Justificação, fundamenta o conceito de naturalismo fraco, a partir da proposta de pensar conjuntamente o mundo da vida com a ideia de um mundo objetivo. Além disso, enfatizaremos como Habermas, agora, separa a verdade da justificação, numa tentativa de conciliar a pragmática da linguagem com o mundo objetivo. $\mathrm{O}$ naturalismo fraco de Habermas evita subordinar ou reduzir a perspectiva interna do mundo da vida ao mundo externo objetivo. Habermas reúne as duas perspectivas teóricas sempre mantidas separadas, à medida que supõe a continuidade entre natureza e cultura. Após a virada linguística, é insustentável, segundo Habermas, a forma clássica de um realismo que se apoia no modelo representativo do conhecimento e na correspondência entre proposição e fatos. Por outro lado, a concepção realista não pode prescindir de um conceito de referência que explique como nós, sob diferentes descrições teóricas, nos referimos aos mesmos objetos. Habermas procura conciliar a dimensão pragmática do mundo da vida, com o mundo objetivo independente do espírito. A argumentação permanece o único meio disponível para se certificar da verdade, à medida que não há outra maneira de examinar as pretensões de verdade tornadas problemáticas. Entretanto, as tentativas de Habermas de abordar questões filosóficas centrais, sem deixar de ser fiel ao pensamento pós-metafísico, conduziram-no a problemas fundamentais, obscuridades, incoerências, ausência de esclarecimentos e soluções.

Palavras-chave: Habermas. Naturalismo Fraco. Verdade. Justificação.

\begin{abstract}
The paper uses Habermas, in Truth and Justification, to justify the concept of weak naturalism, from the bid of using the way of thinking in a lifeword against a natural world. Besides, we will emphasize how Habermas, now, separates the Truth of Justification, an way of arrange the pragmatics of language with the natural world. The Habermas's weak naturalism avoids to subordinate or decrease the internal perspective of the lifeworld to external natural world. Habermas gathers two theoretical perspectives always separated, as suppose the continuity between nature and culture. After the Linguistic Turn, is unthinkable, in according to Habermas, the classic way of realism which rests in a representative model of knowledge and in an harmony among proposition and facts. In other perspective, the realist conception can not dispense a concept of reference which explains how us, under differents theoretical descriptions, refer to the same objects. Habermas seeks reconcile the pragmatic dimension of lifeworld, esprit independent of the natural world. The discussion remains the only mode available to be assure of the truth, considering that is no other way of examine the problematical claims of truth. However, Habermas's attempts of approaching central philosophical issues, while remaining loyal to the postmetaphysical thinking, led him to fundamental problems, obscurity, inconsistencies, absence of explanations and solutions.
\end{abstract}

Keywords: Habermas. Weak Naturalism. Truth. Justification.

\footnotetext{
* Doutorando em Filosofia pela Universidade Federal do Ceará (UFC). Bolsista CAPES. Contato: julianocordeiro81@gmail.com
}

\begin{tabular}{|c|c|l|l|l|l|}
\hline intuitio & $\begin{array}{c}\text { ISSN } \\
1983-4012\end{array}$ & Porto Alegre & Vol.7 $-\mathrm{N}^{\mathrm{o}} .1$ & $\begin{array}{c}\text { Junho } \\
2014\end{array}$ & p.226-238 \\
\hline
\end{tabular}




\section{Um Caminho Entre Quine e Heidegger: a proposta do naturalismo fraco}

Em Verdade e Justificação, Habermas continua sua reflexão sobre o pensamento pósmetafísico, a partir de dois desafios teóricos determinantes para pensarmos sua filosofia: a) A questão ontológica do naturalismo. Trata-se aqui de pensar como é possível compatibilizar a normatividade irrecusável de um mundo da vida, linguisticamente estruturado, no qual já sempre nos encontramos enquanto sujeitos de linguagem e ação, com a contingência de um desenvolvimento histórico-natural das formas sócio-históricas de vida que constituem um mesmo mundo; b) A questão epistemológica do realismo: como conciliar a tese da pressuposição irrecusável de um mundo objetivo independente de nossas descrições e idêntico para todos os observadores, com a tese básica da reviravolta linguística de que não temos acesso diretamente, isto é, não linguisticamente mediado, a uma realidade "nua".

O grande desafio, segundo Habermas ${ }^{1}$, em Verdade e Justificação, é pensar de forma conjunta o primado epistêmico de um mundo linguístico no mundo da vida, com o primado ontológico de uma realidade independente da linguagem, que impõe limitações às nossas práticas. Para Habermas, há, em inúmeras variantes, a oposição entre o naturalismo estrito ou forte de Quine e o idealismo da história do Ser de Heidegger. Numa confrontação com elas, Habermas ${ }^{2}$ introduz a alternativa de um naturalismo fraco (schwache Naturalismus), pois, para ele, o realismo cognitivo, após a virada linguística, pode se vincular ao que Habermas denomina de naturalismo fraco, sem renunciar ao questionamento pragmático-transcendental.

Para Habermas, o naturalismo estrito de Quine alia-se a uma compreensão cientificista de nossas possibilidades de conhecer, uma vez que todo conhecimento deveria sempre deixar-se remeter a procedimentos das ciências empíricas. Segundo Habermas, a continuação naturalista da tradição empirista tem, no entanto, seu preço: uma assimilação objetivista de nossas práticas normativas aos eventos observáveis do mundo. Sujeitos capazes de falar e agir não podem evitar, em seus pensamentos e ações, regular-se por normas e deixar-se afetar por razões. Para Habermas, eles não podem se reconhecer sob a descrição objetivante de Quine.

No naturalismo estrito, desaparece a diferença entre, de um lado, as condições da constituição do mundo (ou de abertura ao mundo), que exigem uma análise conceitual, e, de outro, os estados e eventos que se manifestam no mundo e podem ser causalmente explicados. Além disso, desapareceria, também, a perspectiva de conciliar a "visão interna" das práticas do mundo da vida concebida de modo transcendental, com a "visão externa" de sua gênese explicada em termos causais.

Há, no naturalismo estrito de Quine, uma tradução do saber intuitivo de sujeitos capazes de falar e agir numa linguagem compatível com a das ciências nomológicas. Entretanto, o distanciamento cientificista em relação ao saber intuitivo traz questionamentos ao naturalismo estrito: sujeitos capazes

\footnotetext{
${ }^{1}$ HABERMAS, J. Verdade e Justificação: Ensaios Filosóficos. São Paulo: Edições Loyola, 2004, p.11.

${ }^{2}$ HABERMAS, J. Verdade e Justificação: Ensaios Filosóficos. São Paulo: Edições Loyola, 2004, p.31.
}

\begin{tabular}{|c|c|c|c|c|c|}
\hline intuitio & $\begin{array}{c}\text { ISSN } \\
1983-4012\end{array}$ & Porto Alegre & Vol.7- No.1 & $\begin{array}{c}\text { Junho } \\
2014\end{array}$ & p.226-238 \\
\hline
\end{tabular}


de falar e agir, inseridos em práticas comunicativas, não podem evitar, em seus pensamentos e ações, regular-se por normas e deixar-se afetar por razões.

Por outro lado, Heidegger historificou o a priori de sentido. Há, por assim dizer, um fatalismo de sentido que nos marca para além de nossa consciência, contrapondo-se à autocompreensão de seres autônomos, que se movimentam através de razões na direção de tomadas de posição racionalmente motivadas.

O naturalismo fraco de Habermas, por sua vez, apoia-se na ideia de que nossos processos de aprendizagem, dentro das formas de vida socioculturais, dão continuidade aos processos de aprendizagem evolucionários. Ou seja, ele se radica numa única pressuposição metateórica: nossos processos de conhecimento no quadro das formas de vida sócio-históricas de alguma forma dão continuidade a processos de aprendizagem evolucionários prévios que produziram as estruturas de nossas formas de vida. Portanto, as estruturas transcendentais que possibilitam nossos processos de conhecimento se revelam como resultado de processos de aprendizagem menos complexos de natureza histórico-natural, e, através disso, adquirem seu conteúdo cognitivo.

Tal postura não implica, no entanto, qualquer tipo de reducionismo, como, por exemplo, o naturalismo estrito. Este substitui a análise conceitual de práticas do mundo da vida, por uma explicação cientificista, neurológica e biogenética das operações do cérebro humano. O naturalismo fraco, por sua vez, satisfaz-se com a hipótese de que o equipamento orgânico e o modo de vida cultural do homo sapiens têm uma origem "natural", sendo acessíveis a uma explicação fundamentada na teoria da evolução.

O naturalismo fraco de Habermas evita subordinar ou reduzir a perspectiva interna do mundo da vida ao mundo externo objetivo. Ele reúne as duas perspectivas teóricas sempre mantidas separadas, à medida que supõe a continuidade entre natureza e cultura. A suposição ontológica de um primado genético da natureza obriga também a perspectiva, própria do realismo cognitivo, de um mundo objetivo, independente do espírito.

Habermas tenta escapar tanto da falácia idealista como da naturalista, com seu naturalismo fraco. Este, porém, também é uma tese acerca do todo da realidade, ou seja, do mundo. Segundo Puntel $^{3}$, apesar de não ser reducionista, o naturalismo fraco de Habermas seria mais próximo de Quine do que de Heidegger, haja vista que Habermas pretende considerar em suas análises as teorias científicas, como a da evolução.

Habermas enfatiza que nossos processos de aprendizagem, que são possíveis no interior da estrutura das formas socioculturais de vida, são a continuação de processos de aprendizagem evolutivos anteriores que deram origem a nossas formas de vida. O naturalismo forte de Quine reduz o mundo da vida ao natural, algo que o naturalismo fraco de Habermas não faz. Mas é central para o naturalismo fraco a tese segundo a qual o mundo da vida é um resultado da evolução do mundo

${ }^{3}$ PUNTEL, L. O Pensamento Pós-Metafísico de Habermas: uma crítica. Síntese - Rev. De Filosofia, v.40, n.127, 2013, p.214.

\begin{tabular}{|c|c|l|l|l|l|}
\hline intuitio & $\begin{array}{c}\text { ISSN } \\
1983-4012\end{array}$ & Porto Alegre & Vol.7- $\mathrm{N}^{\mathrm{o}} .1$ & $\begin{array}{c}\text { Junho } \\
2014\end{array}$ & p.226-238 \\
\hline
\end{tabular}


natural. Esta perspectiva está enraizada na analogia entre a evolução natural das espécies, concebida como resultado da "solução de problemas", e nosso próprio processo de aprendizagem, que é possível no âmbito do desenvolvimento sociocultural.

Contudo, o que Habermas chama de naturalismo fraco não é facilmente determinável. Como é possível defender um tipo de naturalismo, mas que seja fraco? Em outras palavras, naturalismo fraco é um conceito que pouco nos diz, sendo essencialmente impreciso. Além disso, Habermas fala de mundo, não no sentido de totalidade dos objetos, mas na perspectiva do mundo natural, no âmbito físico-biológico. Mas um problema permanece: há uma distinção não esclarecida entre mundo vivido e mundo natural.

Segundo Puntel, falta em Habermas um conceito de mundo, como a dimensão que abrange o mundo natural e o mundo da vida, apesar dele criticar a falácia idealista e naturalista. "Ele deveria designar toda a realidade e assim incluir tanto o mundo natural, como cosmo ou processo evolutivo físico-biológico, quanto o mundo da vida, a dimensão da comunicação e ação"4. Habermas não oferece uma explicação sobre a relação entre os dois polos distintos ou de sua unidade. Além disso, a ideia defendida por Habermas de que o mundo da vida é resultado da evolução do mundo natural é fortíssima para não ser suficientemente discutida por ele.

\title{
2 A Necessária Distinção Entre Verdade e Justificação
}

Após a virada linguística, é insustentável, segundo Habermas, a forma clássica de um realismo que se apoia no modelo representativo do conhecimento e na correspondência entre proposição e fatos. Por outro lado, a concepção realista não pode prescindir de um conceito de referência que explique como nós, sob diferentes descrições teóricas, nos referimos aos mesmos objetos. Habermas procura conciliar a dimensão pragmática do mundo da vida, com o mundo objetivo.

\begin{abstract}
A suposição ontológica de um primado genético da natureza obriga também à suposição, própria do realismo cognitivo, de um mundo objetivo, independente do espírito. Todavia, no interior do paradigma linguístico, é insustentável a forma clássica de um realismo que se apoia no modelo representativo do conhecimento e na correspondência entre proposição e fatos. Por outro lado, mesmo após a virada da pragmática linguística, a concepção realista não pode prescindir de um conceito de referência que explique como nós, sob diferentes descrições teóricas, nos referimos ao mesmo objeto (ou a objetos diferentes). Além disso, ela também exige um conceito não-epistêmico de verdade que explique como, sob as premissas de um trato com o mundo impregnado pela linguagem, se pode manter a diferença entre a verdade de um enunciado e a assertibilidade justificada em condições ideais ${ }^{5}$.
\end{abstract}

Segundo Habermas, a importância dada à virada linguística não nos obriga a aceitar um contextualismo forte, no sentido de Richard Rorty. Habermas situa-se no mesmo quadro teórico de

${ }^{4}$ PUNTEL, L. O Pensamento Pós-Metafísico de Habermas: uma crítica. Síntese - Rev. De Filosofia, v.40, n.127, 2013, p.214.

${ }^{5}$ HABERMAS, J. Verdade e Justificação: Ensaios Filosóficos. São Paulo: Edições Loyola, 2004, p.17.

\begin{tabular}{|c|c|c|c|c|c|}
\hline intuitio & $\begin{array}{c}\text { ISSN } \\
1983-4012\end{array}$ & Porto Alegre & Vol.7- $\mathrm{N}^{\mathrm{o}} .1$ & $\begin{array}{c}\text { Junho } \\
2014\end{array}$ & p.226-238 \\
\hline
\end{tabular}


Rorty, pretendendo, contudo, guardar a objetividade do pensamento, propondo uma forma de pensar que nos torne capazes de enfrentar racionalmente os grandes desafios de nossa época ${ }^{6}$. Habermas defende a necessidade de se manter ainda uma perspectiva realista e objetiva, levando sempre em consideração a pragmática.

Habermas considera que o pragmatismo perdeu um aspecto determinante da problemática da verdade presente na teoria correspondencial, a saber, a dimensão da validade incondicionada. Para ele, não podemos nos opor a um mundo objetivo feito de entidades independentes da descrição que fazemos delas. Temos que pressupor não apenas na fala, como também na ação, um mundo objetivo que não foi construído por nós e que é o mesmo para todos.

Rorty $^{7}$, por sua vez, explica que não existe uma realidade para além daquela que se mostra no dia a dia. Ele critica aquilo que denomina de doença platônica. Esta pressupõe um mundo objetivo, das essências, independente da linguagem. Rorty critica a perspectiva tradicional de que há verdades a serem descobertas. Para ele, a verdade não seria encontrada, e sim construída. O conceito tradicional de objetividade não faz sentido para Rorty, pois a objetividade não pode ser estabelecida pelo relacionamento correto do sujeito com o objeto, em que a mente espelharia o real.

Como explica Rorty ${ }^{8}$, conhecer, na perspectiva da tradição, seria representar o que é exterior à mente, a fim de que esta se torne apta a espelhar o mundo objetivo. Não é à toa, diz Rorty, que a preocupação central da filosofia foi sempre ser uma teoria geral da representação. A mente, portanto, seria um grande espelho contendo várias representações.

$\mathrm{O}$ conceito de verdade, em Rorty, estaria relacionado àquilo que podemos justificar num determinado contexto. "Assim, penso que o tópico "verdade" não se pode tornar relevante para a política democrática, e que os filósofos dedicados a essa política deveriam prender-se ao "tópico" justificação". Para Rorty, estamos sempre engajados numa conversação direcionada a gerar concordância ou, ao menos, um desacordo interessante, de uma maneira que nos ajude a enfrentar a vida.

Habermas, partindo também da filosofia do segundo Wittgenstein, aceita várias das teses de Rorty sobre a verdade e o conhecimento. Porém, ele, pretende salvar a dimensão do mundo objetivo, levando em conta, ao mesmo tempo, a pragmática. O que distingue a posição de Habermas do pragmatismo de Rorty é a separação da justificação dos contextos concretos de ação, da verdade, que implica um sentido incondicionado independente do contexto de ação, não podendo ser relativizado a determinadas pessoas, grupos ou épocas. Em Habermas, há uma pretensão à universalidade. Portanto,

${ }^{6}$ OLIVEIRA, M. Neo-Pragmatismo de Richard Rorty x Teoria da Ação Comunicativa de Jürgen Habermas. Revista Educação em Debate, Fortaleza: V. 1 e 2, n. 53 e 53, 2007, p.30.

${ }^{7}$ RORTY, R. A Filosofia e o Espelho da Natureza. Lisboa: Publicações Dom Quixote, 1988, p.62.

${ }^{8}$ RORTY, R. A Filosofia e o Espelho da Natureza. Lisboa: Publicações Dom Quixote, 1988, p.250.

${ }^{9}$ RORTY, R. Verdade, Universalidade e Política Democrática (Justificação, contexto, racionalidade e pragmatismo). In: SOUZA, J. C. de. (org). Filosofia, Racionalidade, Democracia: os debates Rorty e Habermas. São Paulo: Editora Unesp, 2005, p.107.

\begin{tabular}{|c|c|l|l|l|l|}
\hline intuitio & $\begin{array}{c}\text { ISSN } \\
1983-4012\end{array}$ & Porto Alegre & Vol.7- $\mathrm{N}^{\mathrm{o}} .1$ & $\begin{array}{c}\text { Junho } \\
2014\end{array}$ & p.226-238 \\
\hline
\end{tabular}


se Rorty defende uma postura antifundacionista, Habermas enfatiza uma fundamentação fraca no agir comunicativo.

Habermas fala acerca de um conceito não epistêmico de verdade, que explique, partindo da ideia de um mundo impregnado pela linguagem, como se pode manter a diferença entre a verdade de um enunciado e a assertibilidade justificada em condições ideais. Habermas combate a perspectiva de Rorty de que a verdade pode ser equiparada à justificação.

Esse conceito não-epistêmico de verdade, que se manifesta no agir apenas operativamente e, portanto, de modo não-temático, confere às pretensões de verdade discursivamente tematizadas um ponto de referência que transcende toda justificação A meta das justificações é encontrar uma verdade que ultrapasse todas as justificações. Por certo, essa referência transcendente assegura a diferença entre verdade e aceitabilidade racional, mas põe os participantes do discurso numa situação paradoxal. De um lado, sem acesso direto às condições de verdade, eles só podem resgatar as pretensões de verdade graças à força de convicção das boas razões; de outro, as melhores razões estão sob a reserva da falibilidade, de modo que, justamente onde a verdade e a falsidade dos enunciados são tematizados, o abismo entre aceitabilidade racional e verdade não pode ser transposto ${ }^{10}$.

Habermas afirma que podemos fracassar "perante a realidade". Erros revelariam uma falta de saber empírico confiável. Isto diz respeito à validade sobre algo no mundo objetivo. Os sujeitos supõem, em comum, um mundo objetivo como totalidade dos objetos que podem ser tratados e apreciados. É justamente o conceito de fracasso performativo que nos conduz a uma pressuposição formal de nossas ações linguísticas e de nossas intervenções no mundo objetivo, enquanto sistema de possíveis referências.

Para Habermas, o mundo só conquista objetividade ao tornar-se válido enquanto mundo único para uma comunidade de sujeitos capazes de agir e utilizar a linguagem. O conceito abstrato de mundo é condição necessária para que os sujeitos que agem comunicativamente possam chegar a um entendimento mútuo sobre o que acontece no mundo ou sobre o que se deve fazer nele.

Os participantes do discurso assumem a mesma pressuposição formal de um mundo independente de nós, de nossas descrições, de nossos esquemas conceituais. A partir da resistência da realidade, podemos aprender algo à medida que são tematizadas nossas convicções. Para Habermas, o uso do predicado "verdadeiro" no sentido de uma validade incondicional significa que sentenças verdadeiras merecem ser aceitas como válidas por qualquer um, em qualquer lugar e contexto. A esta universalidade da validade da verdade corresponde, do lado da referência, a suposição de que o mundo, seja qual for a perspectiva da qual nos referimos a algo nele, é o mesmo para todos. Segundo Habermas, supomos tanto a existência de objetos possíveis dos quais podemos afirmar fatos, como a comensurabilidade de nossos sistemas de referência, que nos permite reconhecer os mesmos objetos sob descrições diferentes.

${ }^{10}$ HABERMAS, J. Verdade e Justificação: Ensaios Filosóficos. São Paulo: Edições Loyola, 2004, p.50.

\begin{tabular}{|c|c|l|l|l|l|}
\hline intuitio & $\begin{array}{c}\text { ISSN } \\
1983-4012\end{array}$ & Porto Alegre & Vol.7- $\mathrm{N}^{\mathrm{o}} .1$ & $\begin{array}{c}\text { Junho } \\
2014\end{array}$ & p.226-238 \\
\hline
\end{tabular}


É certo, diz Habermas, que a legitimidade de uma asserção deve necessariamente ser resgatada discursivamente ou justificada no interior de uma prática compartilhada intersubjetivamente. Contudo, justificação alguma se torna verdade imediatamente. Habermas ${ }^{11}$ outrora definia o sentido de verdade a partir da situação ideal de fala, através dos pressupostos idealizantes de (a) publicidade e total inclusão de todos os envolvidos, (b) distribuição equitativa dos direitos de comunicação, (c) caráter não violento de uma situação que admite apenas a força não coerciva do melhor argumento, e (d) a probidade dos proferimentos de todos os participantes.

Entretanto, Habermas, em Verdade e Justificação, partindo das críticas de Cristina Lafont, Albrecht Wellmer entre outros, afirma que a verdade não pode ser assimilada à situação ideal de fala. "De lá para cá, percebi que essa assimilação não pode dar certo. Reformulei o antigo conceito discursivo de verdade, que não é errado, mas é pelo menos incompleto" ${ }^{12}$.

Albrecht Wellmer $^{13}$, numa crítica a Habermas, destaca que racionalidade e verdade não necessariamente coincidem. Para ele, não podemos afirmar que, havendo consenso racional, exista verdade de imediato. Nada impede que, no futuro, seja considerado falso um consenso atual, o que não implica que agimos irracionalmente. A verdade é sempre algo maior do que a racionalidade dos consensos situados. Todo consenso encontra-se sob reserva, podendo no futuro ser posto em questão mediante razões.

Wellmer argumenta que um conceito de verdade como consenso é insuficiente por não abranger o aspecto da correspondência da verdade. Seria preciso este complemento na teoria discursiva de Habermas. Mesmo que se cumpram as condições ideais de fala, tal fato não significa que as razões alegadas no processo deliberativo tenham sido boas. Um consenso falso pode ser racional no sentido de que foi alcançado sob condições formais de uma situação ideal. Habermas, a partir disso, reformula sua concepção de verdade, distinguindo verdade de justificação.

A partir de Verdade e Justificação, Habermas relaciona o conceito discursivo mantido de aceitabilidade racional, com um conceito de verdade pragmático, não epistêmico, sem assimilar a verdade à assertibilidade ideal. Inicialmente, Habermas apresentou uma teoria consensual da verdade. O que é verdadeiro seria aquilo advindo de um consenso racional e universal, como consequência de um diálogo numa situação ideal de fala. Entretanto, como demonstra Puntel ${ }^{14}$, Habermas viu as dificuldades desta concepção, uma vez que há uma incapacidade de explicar por que mesmo as asserções mais exaustivamente justificadas podem ser falsas. Habermas trabalha atualmente com uma concepção de verdade orientada realisticamente, denominada de realismo epistemológico pragmático.

\footnotetext{
${ }^{11}$ HABERMAS, J. Teoria de la Acción Comunicativa: complementos y estudios previos. Madrid: Ediciones Cátedra, 2001, p.301.

${ }^{12}$ HABERMAS, J. Verdade e Justificação: Ensaios Filosóficos. São Paulo: Edições Loyola, 2004, p.60.

13 Ver em: ALVARENGA, N. Verdade, Contingência e Falibilismo: a teoria discursiva da verdade de J.Habermas à luz das críticas de A.Wellmer. In: Síntese, Belo Horizonte, v.26, n.86, 1999, p.351.

${ }^{14}$ PUNTEL, L. O Pensamento Pós-Metafísico de Habermas: uma crítica. Síntese - Rev. De Filosofia, v.40, n.127, 2013, p.204.
}

\begin{tabular}{|c|c|l|l|l|l|}
\hline intuitio & $\begin{array}{c}\text { ISSN } \\
1983-4012\end{array}$ & Porto Alegre & Vol.7 $-\mathrm{N}^{\circ} .1$ & $\begin{array}{c}\text { Junho } \\
2014\end{array}$ & p.226-238 \\
\hline
\end{tabular}


Os principais passos de Habermas na apresentação e explicação de sua nova concepção pragmático-realista da verdade são os seguintes: a) O ponto de partida são pretensões de verdade feitas no mundo da vida; b) A verdade é conceitualmente (não epistemologicamente) desconectada da justificação. A verdade é transcendente à justificação; c) A verdade implica uma referência a um mundo objetivo, independente; d) A verdade articula a conexão entre a sentença/proposição qualificada como verdadeira e o mundo.

Habermas explica que, argumentos que nos convencem da verdade de "p", podem se revelar falsos em outra situação epistêmica. Ou seja, por mais que "p" seja bem justificado, ele pode ainda se revelar falso. A argumentação permanece, reforça Habermas, o único meio disponível para se certificar da verdade, de modo que não há outra maneira de examinar as pretensões de verdade tornadas problemáticas. Entretanto, a justificação não pode ser validada ainda como verdade. Habermas, então, pretende salvar a dimensão do mundo objetivo.

Ele estabelece um conceito de verdade, em que as pretensões de validade transcendam ao mesmo tempo toda justificação: “[...] depois da destranscendentalização do sujeito cognoscente, continua a existir uma lacuna entre o que é verdadeiro e o que conta como justificado ou racionalmente aceitável para nós" ${ }^{\prime 15}$. Habermas pretende assegurar a diferença entre verdade e aceitabilidade racional. Contudo, tal diferença coloca os sujeitos numa situação paradoxal. De um lado, sem acesso direto às condições de verdade, eles só podem resgatar as pretensões de verdade por meio de boas razões; de outro, as melhores razões são também falíveis. Portanto, Habermas defende que o abismo entre aceitabilidade racional e verdade não pode ser transposto, à medida que todo acordo alcançado pela justificação é também falível.

Habermas destaca que verdade e falibilidade são dois lados de uma mesma moeda. Ele entende que falta à justificação, no sentido de Rorty, uma referência aos objetos. Nesse sentido, as pretensões de verdade devem transcender o contexto, não se satisfazendo apenas com a justificação alcançada. $\mathrm{O}$ verdadeiro, para Habermas, deve ser defendido em todos os contextos possíveis.

Segundo Habermas, uma concepção que faça justiça à intuição realista de um mundo que existe independente de nós, mesmo sem a representação de uma correspondência entre proposições e fatos, favorece o projeto de explicar os aspectos nos quais a verdade e a correção ao mesmo tempo se assemelham e se distinguem. Em suma, a verdade é um conceito que transcende toda justificação, não podendo ser identificada com o conceito de assertibilidade idealmente justificada.

De acordo com Habermas, a conexão interna entre verdade e justificação não é uma questão epistemológica. Aqui não está em jogo a representação correta da realidade, mas uma práxis que não pode vir abaixo. O entendimento mútuo não pode funcionar sem que os envolvidos se refiram a um único mundo objetivo, dentro de um espaço público intersubjetivamente partilhado. O conceito discursivo de verdade não é exatamente falso, mas insuficiente: ele não explica o que nos autoriza a ter

${ }^{15}$ HABERMAS, J. Agir Comunicativo e Razão Destranscendentalizada. Rio de Janeiro: Tempo Brasileiro, 2002, p.44.

\begin{tabular}{|c|c|l|l|l|l|}
\hline intuitio & $\begin{array}{c}\text { ISSN } \\
1983-4012\end{array}$ & Porto Alegre & Vol.7- $\mathrm{N}^{\mathrm{o}} .1$ & $\begin{array}{c}\text { Junho } \\
2014\end{array}$ & p.226-238 \\
\hline
\end{tabular}


por verdadeiro um enunciado suposto como idealmente justificado. Desta forma, asserções bem justificadas podem se revelar falsas: a verdade deve transcender qualquer contexto de justificação.

O conceito habermasiano de verdade deixa intacta a força racionalizante própria de uma forma de argumentação pública e inclusiva, descentrada entre pessoas de direitos iguais, mas relacionando sempre com algo do mundo objetivo. A correção de juízos e normas morais, por sua vez, não dispõe de tal ponto de referência que transcenda toda justificação. O conceito da "correção normativa" se reduz à assertibilidade racional numa situação ideal de fala.

Puntel destaca uma crítica a Habermas, que nos aponta para uma dimensão não aprofundada. $\mathrm{Ele}^{16}$, com razão, critica Habermas, à medida que este rejeita a teoria tradicional da verdade, sem oferecer uma explanação mínima do que ele chama de conexão ou entrelaçamento de verdade e mundo. Sua concepção realista pragmática permanece vaga, uma vez que há uma dicotomia entre mundo da vida e mundo objetivo. Este, em Habermas, permanece sempre intocado e inalterado.

\section{O Estatuto do Mundo Objetivo na Pragmática Habermasiana.}

Habermas defende uma concepção realista de mundo objetivo, como não igual ao mundo vivido, à medida que ele o caracteriza como um mundo de objetos independentes. Habermas chega ao mundo objetivo somente através de análises das ações e discursos que os falantes e agentes realizam no processo comunicativo. Mas isto não transcende a dimensão da comunicação. Em realidade, Habermas sempre privilegia a dimensão pragmática em relação à semântica.

Ele supõe que o "próprio mundo" é o "próprio mundo" apenas se permanecer completamente intocado pela linguagem. Habermas separa fatos de objetos. Ele não menciona a perspectiva de que ao identificar os objetos como elementos do "próprio mundo", nós já estamos falando acerca desses objetos pertencentes ao "próprio mundo". Aqui aparece como pano de fundo a antiga crítica de Hegel a Kant.

\footnotetext{
${ }^{16}$ Embora nosso artigo não explicite a teoria filosófica de Puntel, por questão de objetividade, vale a pena entendermos o lugar de onde Puntel realiza sua crítica a Habermas, na sua obra Estrutura e Ser. Puntel, em seu projeto de uma nova ontologia, a partir do modelo pós-transcendental, que concilia reviravolta linguística com ontologia, enfatiza ser absurda a ideia de se fazer um enunciado sobre algo, afirmando, ao mesmo tempo, que esse algo não é expressável. Segundo Puntel, a expressabilidade é uma determinação imanente do mundo. Para ele, devemos aceitar pelo menos uma linguagem (um sistema semiótico) que contenha uma quantidade não enumerável de expressões. Devemos cogitar não só uma linguagem desse tipo, mas uma pluralidade de tais linguagens. Puntel defende a existência de uma dimensão pura da exposição ou da linguagem, isto é, uma dimensão sem falantes/sujeitos. A ideia da expressabilidade do mundo é central no pensamento de Puntel. Sua visão diverge de todas as concepções de linguagens que trabalham com a perspectiva de um sistema semiótico de comunicação, como em Habermas. Puntel defende uma linguagem onde falantes e sujeitos são despotencializados. Ou seja, haveria uma linguagem não criada pelos sujeitos, pertencente ao mundo enquanto tal. Desta forma, seria preciso superar o abismo e a cesura entre um "lado que é em si" e um "lado moldado pelo nosso espírito". A linguagem defendida por Puntel é denominada de maximal ou absolutamente universal: ela é a linguagem que expressa o mundo e o ser. A linguagem maximal não existe em lugar nenhum, mas ao mesmo tempo ela se encontra em toda parte, à medida que nada existe que não seja ou não possa ser articulado em forma dessa linguagem. A linguagem maximal é imanente ao mundo: "Essa estruturalidade não é produção ou invenção humana; ela é resultado da própria expressabilidade da realidade" (PUNTEL, 2008, p.529).
}

\begin{tabular}{|c|c|l|l|l|l|}
\hline intuitio & $\begin{array}{c}\text { ISSN } \\
1983-4012\end{array}$ & Porto Alegre & Vol.7 $-\mathrm{N}^{\circ} .1$ & $\begin{array}{c}\text { Junho } \\
2014\end{array}$ & p.226-238 \\
\hline
\end{tabular}


Se os fatos acerca dos objetos não têm um status ontológico, então somos confrontados com uma declaração incorreta. Com efeito, para que tenha um significado inteligível, "ser acerca de um objeto" deve ser entendido como "alcançar" ou "atingir" ou "concernir" o próprio objeto; é algo sem sentido declarar um fato acerca de um objeto e então defender que este fato nada tem a ver com o objeto. Se o fato expresso nada tem a ver com o objeto, o objeto permaneceria em um esplêndido isolamento, desconhecido, inarticulado. O processo de aprendizagem que torna possível a expressão de fatos acerca dos objetos não teria qualquer sentido $^{17}$.

Habermas defende uma concepção nominalista do mundo: o mundo é a totalidade de objetos dos quais podemos estabelecer fatos. Segundo Habermas, os fatos são o que nós declaramos acerca dos objetos. Habermas enfatiza que o nominalismo é menos suspeito do que outras posições ontológicas, especialmente as posições que atribuem um status ontológico aos fatos. De acordo com Puntel, o argumento de Habermas é incoerente, pois se os fatos têm uma relação essencial com a linguagem, o mesmo deve ser dito dos objetos. Se os fatos estão entrelaçados com a linguagem porque podem ser expressos, o mesmo ocorre com os objetos. Estes podem ser referidos a. Habermas erroneamente defende que apenas os fatos são tocados pela linguagem, não os objetos.

Há, em Habermas, um abismo que separa a dimensão pragmática da semântica, embora ele sempre argumente que são duas perspectivas inseparáveis. Segundo Puntel, do pressuposto metodológico fundamental da razão comunicativa, Habermas deriva uma consequência temática drástica, ou seja, a restrição do tema da filosofia à dimensão do mundo da vida ${ }^{18}$. De acordo com Puntel, a abordagem pragmática habermasiana considera que as estruturas e práticas da comunicação do mundo da vida são a base única, última e decisiva do pensar filosófico, privilegiando a linguagem natural em sua integralidade.

Habermas distingue entre as funções expositiva (Darstellung) e comunicativa (Kommunikation) da linguagem natural, afirmando que elas se pressupõem mutuamente. Porém, ele privilegia claramente a dimensão pragmática, colocando a semântica em segundo plano. O resultado é que o problema do mundo objetivo em Habermas não é explorado suficientemente em sua teoria. $\mathrm{Ou}$ seja, qual o estatuto do mundo objetivo em Habermas, uma vez que ele é determinante em sua teoria da verdade? Não há uma clareza acerca da relação com a verdade e com o mundo objetivo.

Segundo Habermas, o conceito não-epistêmico de verdade, que se manifesta no agir apenas operativamente e, portanto, de modo não-temático, confere às pretensões de verdade discursivamente tematizadas um ponto de referência que transcende toda justificação. Habermas afirma que a meta das justificações é encontrar uma verdade que ultrapasse todas as justificações. Por outro lado, Habermas continua defendendo que apenas temos acesso à verdade através das justificações.

${ }^{17}$ PUNTEL, L. O Pensamento Pós-Metafísico de Habermas: uma crítica. Síntese - Rev. De Filosofia, v.40, n.127, 2013, p.206.

${ }^{18}$ OLIVEIRA, M. É a Filosofia uma Pragmática? In: Habermas 80 anos. Rio de Janeiro, Tempo Brasileiro, 2010, p.126.

\begin{tabular}{|c|c|l|l|l|l|}
\hline intuitio & $\begin{array}{c}\text { ISSN } \\
1983-4012\end{array}$ & Porto Alegre & Vol.7 $-\mathrm{N}^{\circ} .1$ & $\begin{array}{l}\text { Junho } \\
2014\end{array}$ & p.226-238 \\
\hline
\end{tabular}


Habermas fala da importância de ser reconhecer a dimensão da validade incondicionada, mas não avança para além de tal afirmação. Se há a necessidade de separar verdade de justificação, Habermas teria que aprofundar e tematizar o que ele está chamando de verdade e mundo objetivo. Ou seja, que algo é esse que está para além da justificação e que, ao mesmo tempo, pode pôr abaixo a melhor das justificações, no mesmo instante em que só temos acesso ao mundo objetivo pelas próprias justificações?

Habermas elabora uma teoria filosófica centrada na dimensão comunicativa (pragmática). Seria a partir dela que outras dimensões poderiam ser compreendidas. Percebemos que a dimensão expositiva (semântica) é posta em segundo plano. Em Habermas, o modo como as coisas do mundo são apreendidas e denominadas se orienta no contato comunicativo entre pessoas. O mundo objetivo, para Habermas, se reduz ao quadro referencial da comunicação. Ele é apenas considerado de tal modo que a interação entre pessoas se faça possível.

A preocupação de Habermas não é compreender o mundo enquanto tal, mas considerá-lo à medida que o entendimento mútuo se torne possível. Há o abandono da ontologia. Esta continua rejeitada, e a realidade se faz valer através apenas do fracasso performativo de nossos esquemas conceituais, emergindo enquanto algo independente deles como um postulado formal sem o qual nem a ação simbólica nem a instrumental no mundo seriam possíveis.

Habermas, de fato, é coerente, em sua filosofia teórica, com sua preocupação em distinguir a verdade da justificação, tendo em vista também as questões de sua filosofia prática, seja no debate sobre o diálogo entre secularismo e religião na democracia, bem como nas questões acerca do multiculturalismo, da política deliberativa, da tolerância, da constelação pós-nacional etc. Como enfatiza Delamar Dutra ${ }^{19}$, Habermas pretende que fortes exigências comunicativas sejam capazes, a partir de si mesmas, de dar um caráter de transcendência à correção normativa, colocando a justificação racional ofertada num procedimento discursivo, em analogia com a verdade que também transcende toda justificação.

\section{A Relação Entre Correção Normativa, Verdade e Justificação.}

Assim como a verdade é traduzida num conjunto de ações pragmáticas que a põe em contato com um mundo objetivo, independente de nossos conceitos, a correção normativa também é traduzida num conjunto de posições valorativas, criando vínculos axiológicos, convicções que guiam a ação. Tal qual na verdade, a separação entre o justo e o bom visa a resgatar a validade moral, num nível mais abstrato, frente ao desmoronamento das tradições morais, através da modernidade.

19 DUTRA, D. Da Revisão do Conceito Discursivo de Verdade em Verdade e Justificação. Ethics@. Florianópolis, v.2, n.2, 2003, p.230.

\begin{tabular}{|c|c|c|c|c|c|}
\hline intuitio & $\begin{array}{c}\text { ISSN } \\
1983-4012\end{array}$ & Porto Alegre & Vol.7- $\mathrm{N}^{\mathrm{o}} .1$ & $\begin{array}{c}\text { Junho } \\
2014\end{array}$ & p.226-238 \\
\hline
\end{tabular}


Como afirma María Elena Candioti ${ }^{20}$, a distinção proposta por Habermas, entre verdade e justificação, relaciona-se igualmente com o alcance discursivo no âmbito moral. Enquanto a ideia da verdade tem referência no mundo objetivo, a validade de uma norma no mundo social consiste na perspectiva de ser reconhecida à luz da situação ideal de fala. É certo que a correção normativa não tem um ponto de referência a objetos que se exige dos enunciados verdadeiros. As convicções morais não são questionadas pela resistência do mundo objetivo, mas sim por dissensos no mundo social.

Numa analogia ao que ocorre no debate sobre verdade e justificação na filosofia teórica, Habermas, na filosofia prática, mantém a perspectiva de se partir do contexto, mas igualmente ir além do contexto. Habermas entende que, no caso da validade deontológica, a ideia regulativa é a da inclusão mútua de sujeitos em princípio estranhos entre si, num mundo de relações interpessoais possibilitadas por uma ordem justa. Mesmo que a correção normativa se vincule às condições de justificação, no discurso, há igualmente um momento deontológico que se apresenta como incondicionado.

As condições de verdade são a medida para sabermos se um proferimento preenche ou não sua função de representação. Contudo, o preenchimento da função expressiva e interativa também se mede em condições análogas às da verdade. Isso leva Habermas ${ }^{21}$ a introduzir a sinceridade subjetiva e a correção normativa como conceitos para a validade de atos de fala, os quais têm analogia com a verdade. Essas relações da ação de fala, com intenções de falantes e destinatários, também podem ser pensadas de acordo com o modelo de uma relação com o mundo objetivo, embora este não seja a pretensão da correção normativa.

Se Habermas acerta na proposta de separar a verdade da justificação, considerando-se o problema da universalidade e da objetividade (de um mesmo mundo para todos), ele, ao mesmo tempo, não consegue esclarecer, no âmbito teórico, como ocorre a relação da co-originaridade entre exposição e comunicação.

A filosofia de Habermas ignora ou tenta fazer desaparecer questões filosóficas que tradicionalmente seriam chamadas metafísicas. As tentativas de Habermas de abordar questões filosóficas centrais, sem deixar de ser fiel ao pensamento pós-metafísico, conduziram-no a problemas fundamentais, obscuridades, incoerências, ausência de esclarecimentos e soluções.

Mesmo que Habermas se defina como um realista nas questões epistêmicas (segundo um viés pragmático) e um construtivista nas questões morais, os temas de sua filosofia teórica influenciam igualmente sua filosofia prática, pois as questões da correção normativa são análogas, como vimos antes, às da verdade. Afinal, as pretensões à verdade proposicional, à correção normativa e à autenticidade subjetiva se cruzam no horizonte do mundo da vida que se abre linguisticamente a todos.

${ }^{20}$ CANDIOTI, M. El Realismo Pragmático en la Concepción Habermasiana de la Verdad. In: PINZANI, A; LIMA, C; DUTRA, D (Orgs). O Pensamento vivo de Habermas: uma visão interdisciplinar. Florianópolis: Nefipo, 2008, p.49.

${ }^{21}$ HABERMAS, J. Pensamento Pós-metafísico: Estudos Filosóficos. Rio de Janeiro: Tempo Brasileiro, 1990, p.149.

\begin{tabular}{|c|c|l|l|l|l|}
\hline intuitio & $\begin{array}{c}\text { ISSN } \\
1983-4012\end{array}$ & Porto Alegre & Vol.7- $\mathrm{N}^{\mathrm{o}} .1$ & $\begin{array}{c}\text { Junho } \\
2014\end{array}$ & p.226-238 \\
\hline
\end{tabular}




\section{Referências}

ALVARENGA, N. Verdade, Contingência e Falibilismo: a teoria discursiva da verdade de J.Habermas à luz das críticas de A.Wellmer. In: Síntese, Belo Horizonte, v.26, n.86, 1999, p.347-373.

CANDIOTI, M. El Realismo Pragmático en la Concepción Habermasiana de la Verdad. In: PINZANI, A; LIMA, C; DUTRA, D (Orgs). O Pensamento vivo de Habermas: uma visão interdisciplinar. Florianópolis: Nefipo, 2008, p.34-50.

DUTRA, D. Da Revisão do Conceito Discursivo de Verdade em Verdade e Justificação. Ethics@. Florianópolis, v.2, n.2, 2003, p.219-231.

HABERMAS, J. Pensamento Pós-metafísico: Estudos Filosóficos. Rio de Janeiro: Tempo Brasileiro, 1990. 2001 Teoria de la Acción Comunicativa: complementos y estudios previos. Madrid: Ediciones Cátedra, . Agir Comunicativo e Razão Destranscendentalizada. Rio de Janeiro: Tempo Brasileiro, 2002. Verdade e Justificação: Ensaios Filosóficos. São Paulo: Edições Loyola, 2004.

McCARTHY, T. La Teoria Crítica de Jürgen Habermas. 5.ed. Madrid: Tecnos, 2013.

OLIVEIRA, M. Neo-Pragmatismo de Richard Rorty x Teoria da Ação Comunicativa de Jürgen Habermas. Revista Educação em Debate, Fortaleza: V. 1 e 2, n. 53 e 53, 2007.

126. É a Filosofia uma Pragmática? In: Habermas 80 anos. Rio de Janeiro, Tempo Brasileiro, 2010, p.103-

PUNTEL, L. Estrutura e Ser: Um quadro referencial teórico para uma filosofia sistemática. São Leopoldo: Editora Unisinos, 2008.

O Pensamento Pós-Metafísico de Habermas: uma crítica. Síntese - Rev. De Filosofia, v.40, n.127, 2013, p.173-223.

RORTY, R. A Filosofia e o Espelho da Natureza. Lisboa: Publicações Dom Quixote, 1988.

. Verdade, Universalidade e Política Democrática (Justificação, contexto, racionalidade e pragmatismo).

In: SOUZA, J. C. de. (org). Filosofia, Racionalidade, Democracia: os debates Rorty e Habermas. São Paulo: Editora Unesp, 2005.

Recebido em: 17/03/2014

Aprovado para publicação em: 22/05/2014 